[Agr. Biol. Chem., Vol. 25, No. 6, p. 494 499, 1961]

\title{
Studies on the Chitinolytic Enzymes of Black-koji Mold
}

\author{
Part III. Liquefying Activity and Saccharifying Activity of \\ the Chitinase Preparation
}

By Akira ŌTAKARA

Hiroshima Women's Jr. College, Hiroshima

Received February 27, 1961

\begin{abstract}
It was found that the purified chitinase preparation acts upon glycol chitin resulting in the decomposition to constituent aminosugar, the saccharifying activity being determined by application of the Morgan-Elson reaction. The enzymatic properties of the mold chitinase were investigated by measuring liquefying activity and saccharifying activity. Distinct differences were observed between the two activities, and especially liquefying activity was more stable than saccharifying activity against heat treatment. The chitinase preparation whose saccharifying activity was inactivated by heating was able to decrease the viscosity of glycol chitin solution, with an insignificant production of aminosugar.
\end{abstract}

In the previous paper ${ }^{11}$, the author has carried out the purification of chitinase from wheat-bran culture of Aspergillus niger, using the viscometric method $^{2)}$ for the determination of chitinase activity, and it has been found that the purified chitinase has a powerful property of decreasing the viscosity of $G$. Ch* solution, accompanied by depolymerization of substrate molecule.

The production of AGA* in the hydrolysis of chitin by several chitinase systems has been proved by its isolation ${ }^{3,4)}$ or detection on paper chromatography ${ }^{5,6)}$. However, it is uncertain whether such product is attributed to the action of chitinase itself or to that of different enzyme, because a crude enzyme preparation has been used in those studies. In

* The following abbreviations are used in this paper: G. Ch, glycol chitin; AGA, N-acetylglucosamine; GA, glucosamine.

1) A. Ôtakara, This Journal, 25, 54 (1961).

2) A. Ôtakara, ibid., 25, 50 (1961).

3) P. Karrer and A. Hofmann, Helv., Chim. Acta, 12, 616 (1929).

4) R.H. Hackman, Australian J. Biol. Sci., 7, 168 (1954).

5) H. Veldkamp, Nature, 169, 500 (1952).

6) D.M. Reynolds, J. Gen. Microbiol., 11, 150 (1954). recent report ${ }^{7)}$, Berger and Reynolds have demonstrated that AGA is also produced together with $\mathrm{N}, \mathrm{N}^{\prime}$-diacetylchitobiose from chitin by the resolved chitinase fractions of Streptomyces griseus. In the author's investigation ${ }^{8)}$, it has been supposed that crude enzyme of the mold produces aminosugar from G. Ch, because the Morgan-Elson reaction becomes positive with a rapid reduction of the viscosity.

The present paper is concerned with that the purified chitinase has a property of producing aminosugar from G. Ch and that the enzymatic properties are different between liquefying activity and saccharifying activity.

\section{EXPERIMENTAL}

Substrate and Enzyme Preparation. G. Ch which was prepared by the method described in the previous paper ${ }^{2)}$ was used as the substrate. The purified chitinase preparation was obtained through the procedure of the previous paper ${ }^{1)}$.

7) L.R. Berger and D.M. Reynolds, Biochim. Biophys. Acta, 29, 522 (1958).

8) S. Okimasu and A. Ôtakara, J. Agr. Chem. Soc. Japan, 34, 873 (1960). 

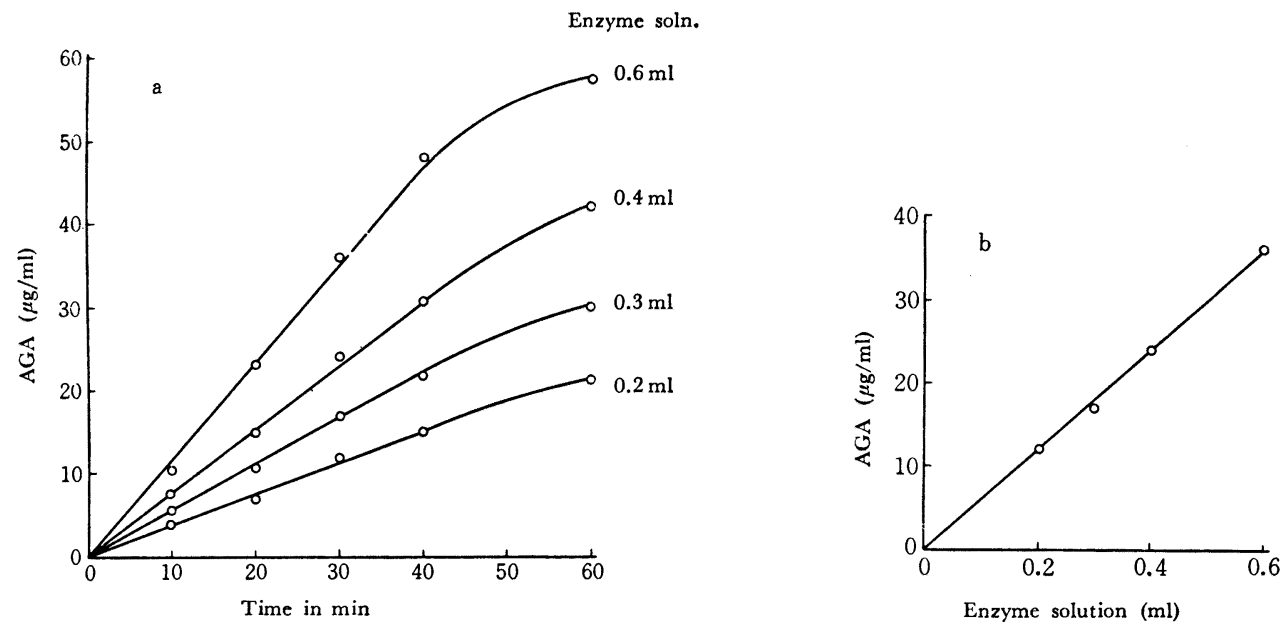

Fig. 1. Time Curves of G. Gh Hydrolysis by Chitinase (a) and Relationship between the Production of AGA and Enzyme Amount (b).

Liquefying Activity. The determination of liquefying activity was carried out by the viscometric method, as reported previously2).

Saccharifying Activity. This activity was determined by measuring aminosugar using the Tracey's modified $\operatorname{method}^{9)}$ of the Morgan-Elson reaction. In this assay, the reaction mixture containing $2 \mathrm{ml}$ of $0.5 \% \mathrm{G}$. Ch solution, one $\mathrm{ml}$ of $0.2 \mathrm{M}$ acetate buffer solution ( $\mathrm{pH}$ 4.2 ) and one $\mathrm{ml}$ of enzyme solution was incubated at $40^{\circ} \mathrm{C}$. After thirty minutes, one $\mathrm{ml}$ of the reaction mixture was poured into $0.3 \mathrm{ml}$ of saturated sodium borate solution in the test tube, which was graduated at a volume of $10 \mathrm{ml}$, with glass stopper, and it was heated in a boiling water bath for seven minutes, then cooled. The test tube was filled up to $10 \mathrm{ml}$ by adding glacial acetic acid and followed by one $\mathrm{ml}$ of Ehrlich reagent to develope the color. In cases in which undepolymerized substrate is present, it was removed by centrifuge in the course of color development. The color intensity was measured by Erma photoelectric colorimeter with green filter, 20 millimeters cell being used. For the calculation of the amount of aminosugar, AGA solution containing the same amount of acetate buffer solution as in the reaction system was used as a standard solution.

The time curves of the production of AGA in the standard reaction system are shown in Fig. 1a. It

9) M.V. Tracey, "Modern Methods of Plant Analysis", Vol. II, 1955 p. 264. Springer-Verlag, Berlin-Göttingen-Heiderberg. was found that the amount of AGA produced in thirty minutes was proportional to the amount of enzyme used (Fig. 1b). Therefore, in the determination of saccharifying activity, enzyme amount that produced $10 \mu \mathrm{g}$ of aminosugar as AGA in one $\mathrm{ml}$ of the reaction mixture under this condition was defined as one unit.

Assay of the Enzymatic Hydrolysis of G. Ch. The production of aminosugar was determined by the Morgan-Elson and the Elson-Morgan reactions, using the method modified by Trace ${ }^{9)}$. In both reactions, AGA and GA hydrochloride were used as reference compounds. Change of the viscosity was measured by Ostwald's viscosimeter.

Paper Chromatography. Paper chromatography was carried out on Tôyô filter paper No. 50, using water saturated phenol under atmosphere of ammonia, and ethylacetate-pyridine-water $(120: 50: 40)$ as the solvents. The spots were detected by the method of Patridge ${ }^{10)}$ in which hexosamine reaction was adopted.

\section{RESULTS}

Production of Aminosugar in the Enzymatic Hydrolysis of $\mathrm{G}$. $\mathrm{Ch}$.

In the course of G. Ch hydrolysis by the purified chitinase, the Morgan-Elson and the Elson-Morgan reactions for the reaction mix-

10) S.M. Partridge, Biochem. J., 42, 238 (1948). 
TABle I. Determination of Aminosugar PRoduced IN THE COURSE OF G. $\mathrm{CH}$ HYDROLYSIS BY CHITINASE

$$
\begin{gathered}
\text { Reaction } \\
\text { time } \\
\text { (min) }
\end{gathered}
$$

$$
10
$$$$
20
$$$$
30
$$$$
40
$$$$
60
$$

90

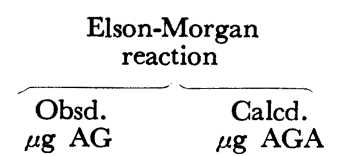

Morgan-Elson reaction

Obsd. $\mu \mathrm{g}$ AGA

$\begin{array}{rl}2.1 & 13.2 \\ 3.7 & 23.0 \\ 6.0 & 37.5 \\ 8.0 & 51.1 \\ 11.0 & 68.9 \\ 13.2 & 82.1\end{array}$

13.2

23.0

51.1

82.1
11.0

24.2

39.7

50.0

66.5

84.9
Reaction mixture contained $5 \mathrm{ml}$ of $0.5 \% \mathrm{G}$. Ch solution, $2 \mathrm{ml}$ of $0.2 \mathrm{M}$ acetate buffer solution ( $\mathrm{pH} 4.2$ ) and $2 \mathrm{ml}$ of enzyme solution (liquefying activity; 37 units). Temperature; $40^{\circ} \mathrm{C}$.

One $\mathrm{ml}$ of the mixture was withdrawn at the time indicated and produced aminosugar was determined by the Elson-Morgan and the Morgan-Elson reactions.

ture are presented in Table I. Under the condition which was used in this experiment, GA gave no color in the Morgan-Elson reaction, while AGA gave about $16 \%$ of the colour given by an equivalent amount of GA in the Elson-Morgan reaction. Furthermore, one mg of $\mathrm{N}, \mathrm{N}^{\prime}$-diacetylchitobiose* gave the color intensity which was equivalent to only $27 \mu \mathrm{g}$ of AGA in the Morgan-Elson reaction. Therefore, when the amount of liberated AGA is calculated from the value which has been observed by the Elson-Morgan reaction as GA, it nearly coincides with the value of AGA

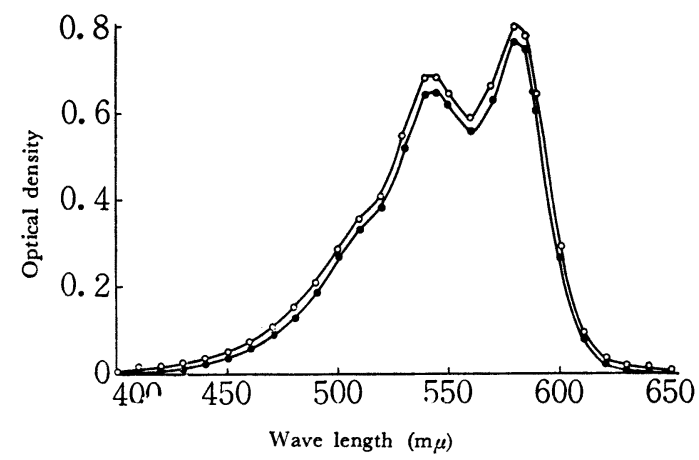

FIG. 2. Absorption Spectrum of the Morgan-Elson Reaction of the Reaction Product and of AGA.$$
\text { - Reaction product }
$$$$
\text { -O- AGA }
$$

* This compound was prepared by acetolysis of chitin and chromatographic separation, as will be described elsewhere.
}

observed by the Morgan-Elson reaction.

As shown in Fig. 2, the absorption spectra of the color produced by the Morgan-Elson reaction of the reaction product and of AGA were identical to each other. The absorption maxima appeared at both 545 and $580 \mathrm{~m}_{\mu}$.

In addition, the detection of produced aminosugar was made by paper chromatography and the spot was identified by a comparison of its $R_{F}$ value with those of AGA and GA hydrochloride. The result is shown in Table II. The reaction product as well as AGA gave purple violet spot by spraying Ehrlich reagent after treatment with alkali solution. On the other hand, GA hydrochloride was made visible when the paper was pretreated with alkali-acetylaceton reagent.

TABle II. PAPER Chromatography of THE REACTION PRODUCT

$$
\begin{aligned}
& \begin{array}{c}
\begin{array}{c}
\text { Reaction } \\
\text { product }
\end{array} \text { AGA GA-HCl } \\
\text { a }
\end{array} \\
& R_{F}\left\{\begin{array}{rrrr}
\text { I } & 0.64 & 0.66 & 0.54 \\
\text { II } & 0.43 & 0.45 & 0.21
\end{array}\right. \\
& \text { Color purple violet purple violet red } \\
& \text { Solvent, I; Water saturated phenol }\left(1 \% \mathrm{NH}_{8}, \mathrm{HC}\right) \\
& \text { II ; Ethylacetate-pyridine-water }=120: 50: 40 \\
& \text { (duplicate developments) }
\end{aligned}
$$

From the results mentioned above, saccharifying activity was determined by application of the Morgan-Elson reaction, as described in the procedure.

The Properties of Liquefying Activity and Saccharifying Activity.

The properties of the purified chitinase were investigated by determining both activities under the standard conditions. As reported previously2), the Morgan-Elson and the Elson-Morgan reactions were negative in the experimental condition of the determination of liquefying activity. Therefore, in order to determine the saccharifying activity, it was necessary to use about ten times the amount of enzyme used for the measurement of liquefving activity.

Optimum pH. The $\mathrm{pH}$-activity curves for 


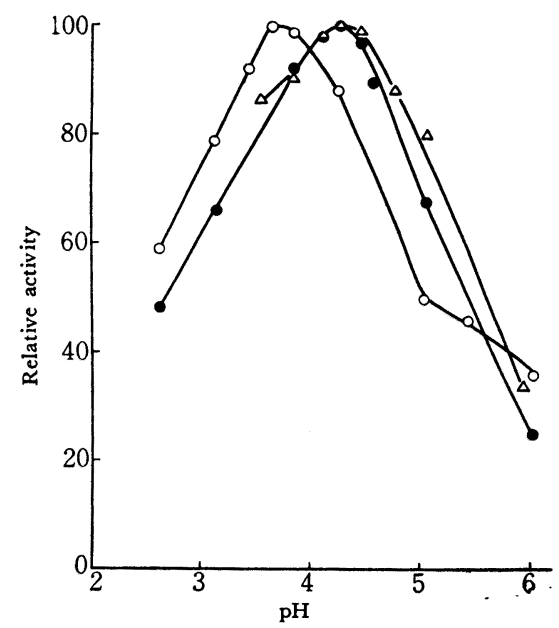

Fig. 3. Effect of $\mathrm{pH}$ on the Both Activities.

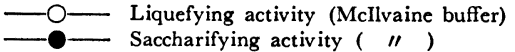

$\triangle-$ Saccharifying activity (Acetate buffer)

the enzymatic hydrolysis of G. Ch are shown in Fig. 3. The optimum $\mathrm{pH}$ for liquefying activity or saccharifying activity was at 3.6 and 4.2, respectively. When McIlvain buffer solution was used, inhibition on the MorganElson reaction by increasing concentration of

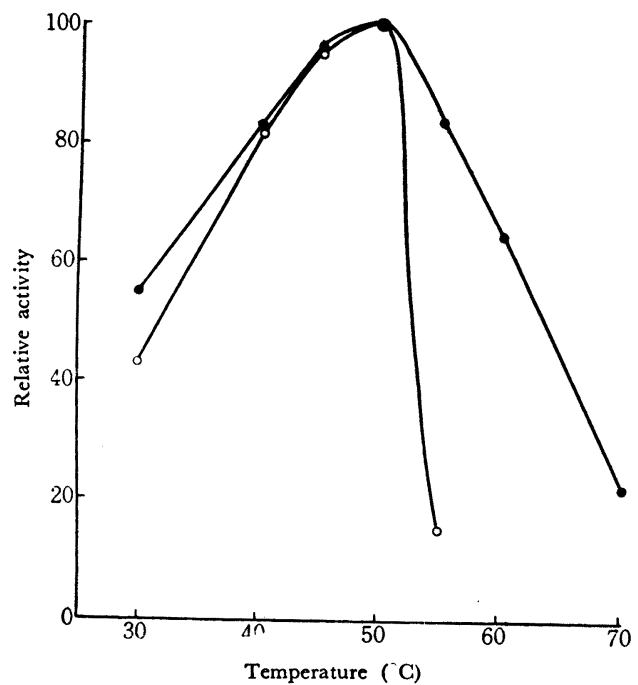

FIG. 4. Effect of Temperature on the Both Activities. - L L - Saccharifying activity citric acid occurred below $\mathrm{pH}$ 3.0.

Optimum Temperature. The effect of temperature on the reactions is shown in Fig. 4. The optimum temperature for both activities was around $50^{\circ} \mathrm{C}$. In liquefying activity a rapid decline of the curve was observed above $50^{\circ} \mathrm{C}$.

pH Stability. The stability of enzyme solution under various pH's is shown in Fig. 5. Enzyme solution was kept under various $\mathrm{pH}$ 's at $30^{\circ} \mathrm{C}$ for twenty hours and both activities were determined. Liquefying activity was rather unstable compared with saccharifying activity in acidic region.

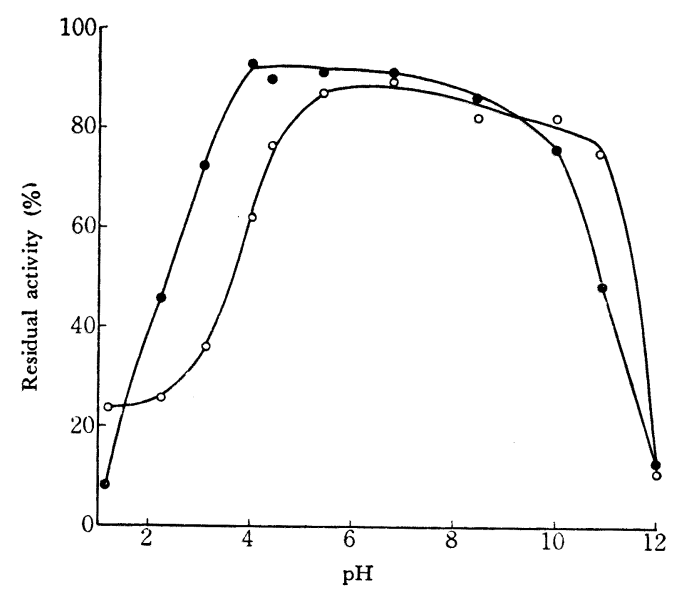

FIG. 5. Effect of $\mathrm{pH}$ on the Stability of Enzyme. - - Liquefying activity

Heat Stability. In Fig. 6 the effect of heat treatment on the stability of enzyme solution was measured at $\mathrm{pH} 6.0$. $(0.005 \mathrm{~m}$ phosphate buffer solution). Distinct difference was found between both activities. After enzyme solution had been heated at $70^{\circ} \mathrm{C}$ for ten minutes, about $75 \%$ of the original activity was recovered in liquefying activity, whereas a remarkable inactivation occurred in saccharifying activity. However, liquefying activity was considerably heat-labile at the optimal $\mathrm{pH}$ and it was completely destroyed by heating under $\mathrm{pH} 3.6$ at $70^{\circ} \mathrm{C}$, for ten minutes. 

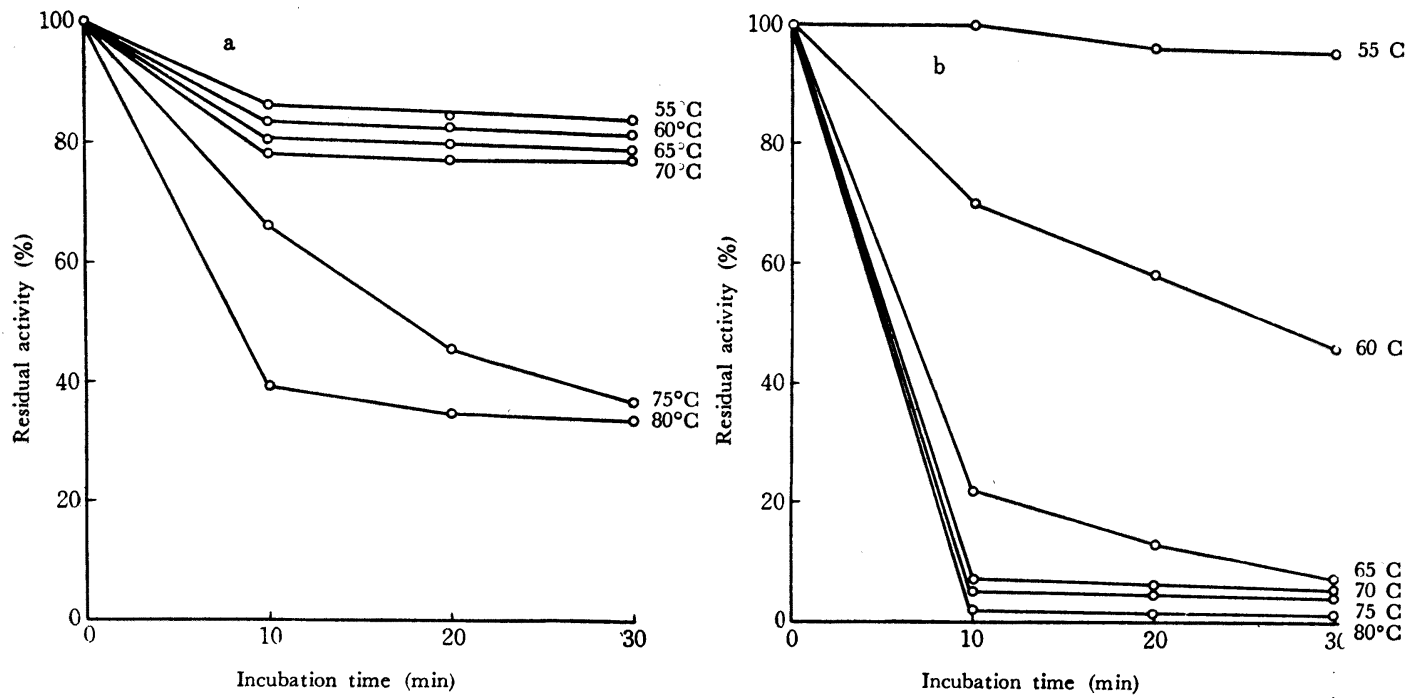

FIG. 6. Effect of Heat Treatment on the Stability of Enzyme.

a) Liquefying activity, b; Saccharifying activity.
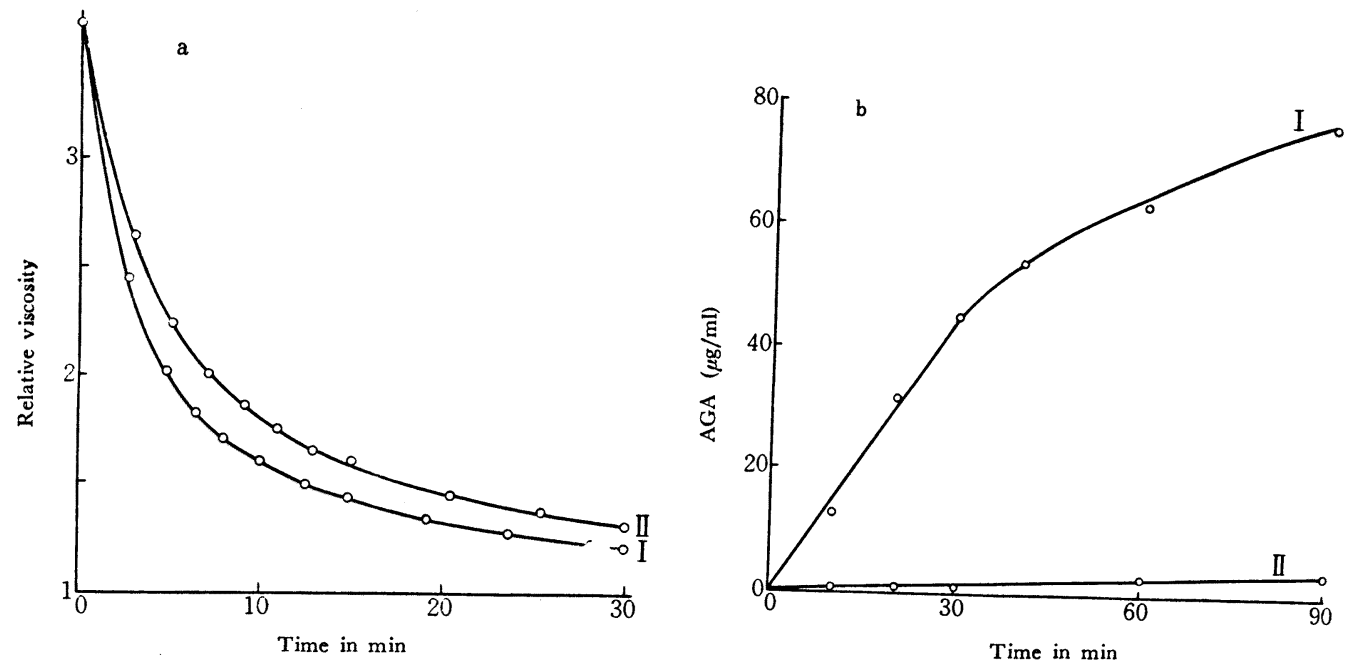

FIG. 7. Effect of Heat Treatment of Enzyme on Viscosity Reduction and the Production of AGA. I; Before heat treatment II; After heat treatment.

a) Viscosity reduction; Reaction mixture contained $5 \mathrm{ml}$ of $0.5 \%$ G. Ch solution, $5 \mathrm{ml}$ of Mcllvaine buffer solution (pH 3.6) and one $\mathrm{ml}$ of enzyme solution (liquefying activity: I; 3.7 units II ; 2.6 units). Temperature, $40^{\circ} \mathrm{C}$. Ten $\mathrm{ml}$ of the mixture was used to measure change of the viscosity.

b) The production of AGA ; Reaction mixture contained $4 \mathrm{ml}$ of $0.5 \% \mathrm{G}$. Ch solution, $2 \mathrm{ml}$ of $0.2 \mathrm{M}$ acetate buffer solution (pH 4.2 ) and $2 \mathrm{ml}$ of enzyme solution (liquefying activity: I; 37 units, II ; 26 units). Temperature, $40^{\circ} \mathrm{C}$.

Inactivation of Saccharifying Activity in the Purified Chitinase Preparation.

The purified chitinase preparation was made nearly free from saccharifying activity by heating it at $70^{\circ} \mathrm{C}$ for ten minutes. The effect of heat treatment of the preparation on 
viscosity reduction and the production of AGA is shown in Fig. 7. After heat treatment, no significant amount of AGA could be produced in spite of the presence of enzyme which was sufficient to decrease the viscosity.

\section{DISCUSSION •}

The experimental results represented in Table I, II and Fig. 2 show that the aminosugar produced by the mold chitinase from G. Ch is not hexosamine but N-acetylhexosamine, probably glycol AGA. Therefore, in the course of saccharification of $\mathrm{G}$. $\mathrm{Ch}$, the production of aminosugar can be determined by application of the Morgan-Elson reaction. It is evident that the purified chitinase acts upon G. Ch resulting in the decomposition to constituent aminosugar, in addition to a rapid reduction of the viscosity.

Differences between liquefying activity and saccharifying activity in the enzymatic properties, especially in the heat stability (Fig. 6), and differences in the course of the enzymatic decomposition of G. Ch (Fig. 7), strongly suggest the possibility that different types of enzymes participate in the depolymerization of substrate molecule and the production of AGA. In the previous communication ${ }^{1)}$, the chitinase preparation which is powerfully active in liquefaction of $\mathrm{G}$. Ch has been obtain- ed in a highly purified state. However, it is concomitant with saccharifying activity which is easily inactivated through heat treatment of the preparation. The present author has succeeded to separate both enzymes each other and the detailed studies will be published in the near future.

The mold chitinase has a optimum $\mathrm{pH}$ in more acidic region than that of Streptomyces chitinase reported by earlier workers ${ }^{7,11)}$ and its heat stability resembles that of one of resolved chitinase fractions obtained from Streptomyces griseus $^{7)}$. Recently, Hamaguchi and Funatsu ${ }^{12)}$ have reported that the viscosity of G. Ch solution decreases by the action of lysozyme. In their communication ${ }^{13)}$, it is very interesting that the enzymatic properties of lysozyme are similar to those of the mold liquefying chitinase and that the production of AGA is very small as compared with the decrease in the viscosity.

Acknowledgements The author wishes to express his sincere thanks to Prof. Y. Ōshima of Kyûshû University for his encouragement and his interest in this work, and also to Dr. S. Okimasu of this college for his kind advice.

11) C. Jeuniaux, Arch. intern. Physiol. Biochim., 66, 408 (1958)

12) K. Hamaguchi and M. Funatsu, J. Biochem., 46, 1659 (1959).

13) K. Hamaguchi, K. Rokkaku, M. Funatsu and K. Hayashi, ibid., 48, 351 (1960). 